\title{
STUDY REGARDING THE PRESENCE OF SOME HEAVY METALS (CHROMIUM, COPPER, MANGANESE AND ZINC) IN THE GREEN WASTE COMPOST
}

\author{
IRINA SMICAL ${ }^{\mathrm{a}}$, ADRIANA MUNTEAN ${ }^{\mathrm{b}}$, \\ VALER MICLE ${ }^{\mathrm{c}}$, ZOLTÁN TÖRÖK ${ }^{\mathrm{d}}$
}

\begin{abstract}
The composting is one of the most effective recycling method of green waste. The presence of some heavy metals, such as chromium, copper, manganese and zinc may influence the compost quality. The bioavailable and unavailable metal forms for plants determined by sequential analysis showed similarities in relation to the percentages of extracted forms. The lowest percentages were recorded for the bioavailable metal forms for plants uptake. Thus, the succession $F 6>F 5>F 4>F 3>(F 1+F 2)$ is characteristic for chromium, the succession $F 5>F 6>F 4>F 3>(F 1+F 2)$ is characteristic for copper and zinc and the succession $\mathrm{F} 5>\mathrm{F} 4>\mathrm{F} 6>\mathrm{F} 3>(\mathrm{F} 1+\mathrm{F} 2)$ is characteristic to the zinc and manganese. Thus, by adding some organic additives, like manure, the micronutrients and heavy metals regime is influenced.
\end{abstract}

Keywords: green waste, compost, manure, heavy metal

a North University Centre of Baia Mare, Technical University of Cluj-Napoca Engineering of Mineral Resources, Materials and Environment Department, Victor Babes str., no. 62A, 430083, Baia Mare, Romania

b Maramureș Water Management System, Someș-Tisa Basinal Water Administration, no. 2, Hortensiei Street, 430294, Baia Mare, Romania

c Technical University of Cluj-Napoca, Faculty of Materials and Environmental Engineering, Department: Environment Engineering and Entrepreneurship of Sustainable Development, 103-105 Muncii Blvd., 400641 Cluj- Napoca, Romania

d Faculty of Environmental Science and Engineering, Babeș-Bolyai University of Cluj-Napoca, 30 Fântânele Street, Cluj County, Romania

*Corresponding author: irina.smical@yahoo.com 


\section{INTRODUCTION}

The bio-waste composting is an efficient method of organic waste conversion into something valuable with positive consequences for the economy and environment. The compost represents a good product for soil, enhancing its quality due to the high nutritive elements content, especially nitrogen and carbon, but also as sorbent for heavy metals in aqueous environment [1].

Even the toxicity of some metals is reduced during composting, the final product may have heavy metals which could be transferred to soil and groundwater [2-4]. From soil, heavy metals may enter the human body through the food chain and could cause ilnesses due to metals toxicity [5]. The manure addition to the compost in order to increase its quality may enhance the heavy metals content by its own metals content [6]. The metals transfer depends to the plant uptake which is directly correlated with metals mobility and bioavailability [7]. A major role in the transferring process plays the chemical forms of the metals and their binding in the soil structure which is strongly influenced by the organic matter content [8-9].

Singh and Kalamdhad [10] showed that during water hyacinth composting process the concentration of some metals, such as $\mathrm{Cr}_{\text {total }}, \mathrm{Cu}^{2+}$, $\mathrm{Mn}^{2+}$ and $\mathrm{Zn}^{2+}$ was increased.

The data presented in this paper complete the study "Influence of Some Natural Organic Additives on the Quality of Vegetal Compost" [11].

\section{RESULTS AND DISCUSSION}

The results of analysis of the final compost samples (18 ${ }^{\text {th }}$ June 2014) [11], were compared with the values provided by the good practices codes regarding the composting issued by the National Institute of ResearchDevelopment for Pedology, Agrochemistry and Environmental Protection NIRDPAEP-IRPA, Bucharest [12], as it is showed in Table 1.

Table 1. The compost conductivity

\begin{tabular}{|c|c|c|c|c|c|}
\hline \multirow{2}{*}{ Analyzed parameter } & \multirow{2}{*}{ Bulk A } & \multirow{2}{*}{ Bulk B } & \multirow{2}{*}{ Bulk C } & \multicolumn{2}{|c|}{ NIRDPAEP-IRPA [12] } \\
\cline { 5 - 5 } & & & & Minimum & Maximum \\
\hline Conductivity, $\mu \mathrm{S} / \mathrm{cm}$ & $2312 \pm 24$ & $2380 \pm 27$ & $1786 \pm 18$ & $<5000$ \\
\hline
\end{tabular}

Results are mean \pm standard deviation of 10 replicates per each group. 
The final values of the conductivity are much below the maximum limit, the lowest value being for bulk $C$ (Table 1) - without organic additives, most probably because of the slowly micro-biological activity in this bulk.

\section{Physical compost features}

The compost colour was dark brown to black and its texture and smell was similar to that of wet soil. The particles size was less than $2 \mathrm{~cm}$ and they were homogenous distributed. However, the bulk $\mathrm{C}$ content was slightly rougher than the other two bulks, which might be explained by the less decomposing of the organic matter.

Statistical analysis performed using simple correlation by calculating the Pearson coefficient showed negative or statistically insignificant correlations for the confidence level of $5 \%$ between different forms of the metals [13] (Table 2).

Table 2. Significant statistical correlation of the different metal forms

\begin{tabular}{|c|c|c|c|c|}
\hline $\begin{array}{c}\text { The form } \\
\text { of the metal }\end{array}$ & Total & F1 & F2 & F3 \\
\hline F1 & $\mathrm{Cr}_{\mathrm{A}} ; \mathrm{Cr}_{\mathrm{C}} ; \mathrm{Zn}_{\mathrm{A}} ; \mathrm{Zn}_{\mathrm{C}}$ & - & - & - \\
\hline F2 & $\mathrm{Mn}_{\mathrm{A}} ; \mathrm{Mn}_{\mathrm{B}}$ & $\mathrm{Cr}_{\mathrm{A}} ; \mathrm{Cr}_{\mathrm{B}} ; \mathrm{Cr}_{\mathrm{C}}$ & - & - \\
\hline F3 & - & - & - & - \\
\hline F4 & - & $\mathrm{Cu}_{\mathrm{C}} ; \mathrm{Mn}_{\mathrm{B}} ;$ & $\mathrm{Cu}_{\mathrm{C}}$ & - \\
\hline F5 & $\mathrm{Cr}_{\mathrm{A}} ; \mathrm{Cr}_{\mathrm{C}}$ & $\mathrm{Cr}_{\mathrm{A}} ; \mathrm{Cr}_{\mathrm{C}}$ & $\mathrm{Cr}_{\mathrm{A}} ; \mathrm{Cr}_{\mathrm{C}}$ & - \\
\hline
\end{tabular}

Note: $X_{y}-X$ - chemical symbol of the metal; $y$-bulk symbol

All analyzed metals in compost showed a decrease of their concentration during composting with the exception of copper, which showed a high value in bulk $C$ (with no additives). This may be explained thought the fact that the oxidations conditions were not met and that this element did not leach despite of the high moisture in the compost. For all metals, the sequential analysis revealed that no more than $1 \%$ of the total extractible metal content might be available for plants uptake (F1+F2).

Significant quantities of metals were found in the fractions most resistant to extraction, unavailable for plants uptake (F3, F4 and F5). About $30-40 \%$ of the metals were in the residual state (F6), considered as constitutive form of the matrix. The percentage of the metal fractions in the total extracted amount allowed the interpretation of the evolution of each metallic element (Figure 1-16). 


\section{The total chromium evolution}

The total chromium showed the extreme values of the chromium concentration of $59.2 \mathrm{mg} \mathrm{kg}^{-1}$ on $24^{\text {th }}$ July 2013 , reaching the maximal compost decomposition phase, towards to $90.6 \mathrm{mg} \mathrm{kg}^{-1}$ at the beginning of the compost process on $29^{\text {th }}$ April 2013 (Figure 1). The initial total chromium concentrations ranged from $81.6 \mathrm{mg} \mathrm{kg}^{-1}$ (in bulk C) to $90.6 \mathrm{mg} \mathrm{kg}^{-1}$ (in bulk A) much below the limit of $3000 \mathrm{mg} \mathrm{kg}^{-1}$ provided by NIRDPAEP-IRPA [12].

The bulks $A$ and $B$ (with organic additives) showed a decrease of the total chromium concentration up to the decomposition phase $\left(24^{\text {th }}\right.$ July 2013) thereafter the values began to increase but however to the values lower by 1.08 times in bulk $B$ and by 1.25 times in bulk $A$ towards to the initial ones. In bulk $C$ the evolution of the total chromium decreased by 1.15 time towards the initial values (Figure 1).

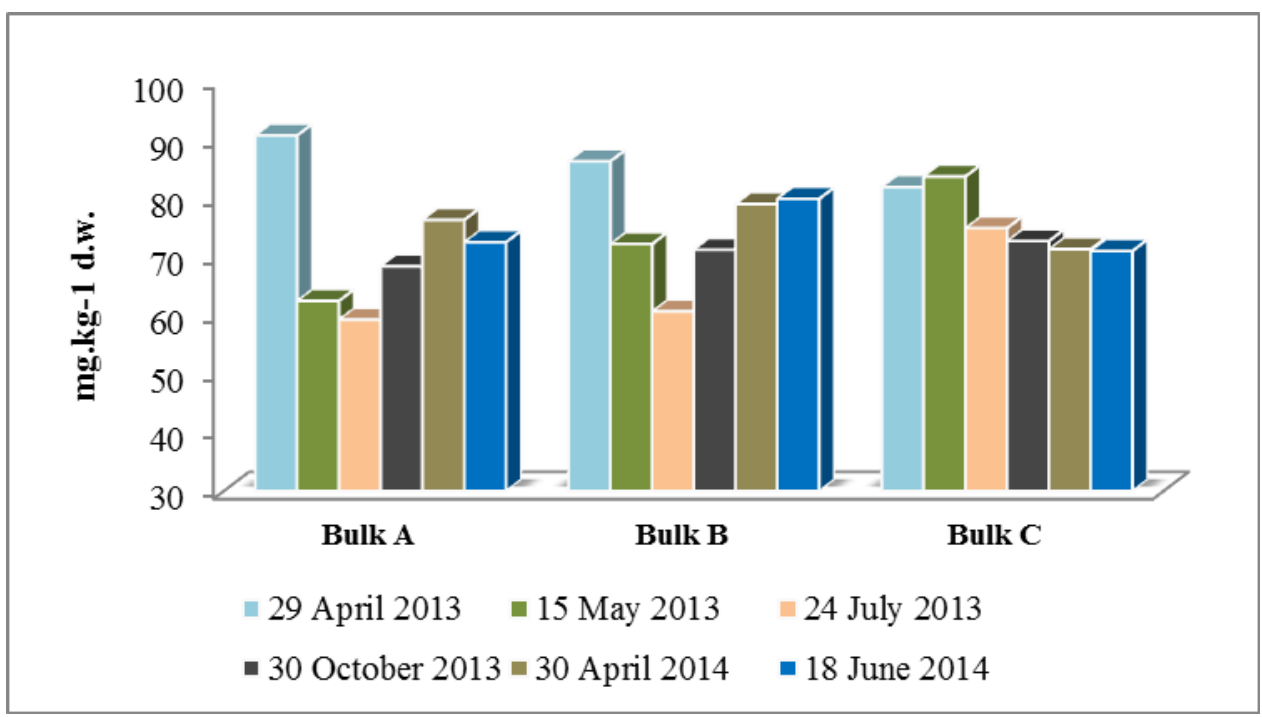

Figure 1. The total chromium in compost

In bulks $A$ and $B$ for chromium, the forms F3 (organically bound "mobilisable”) and F4 (organically complexed or carbonates „mobilisable”) are below $15 \%$ of the total extracted, while in bulk $C$ these forms showed values over $15 \%$ (Figure 2, 3, 4). It is noticeable that in all bulks, the form F5 (sulfides „mobilisable”) has negatively evolved during composting likely to soluble forms F1 and F2 of the metal (Figure 2, 3, 4). 
STUDY REGARDING THE PRESENCE OF SOME HEAVY METALS ...

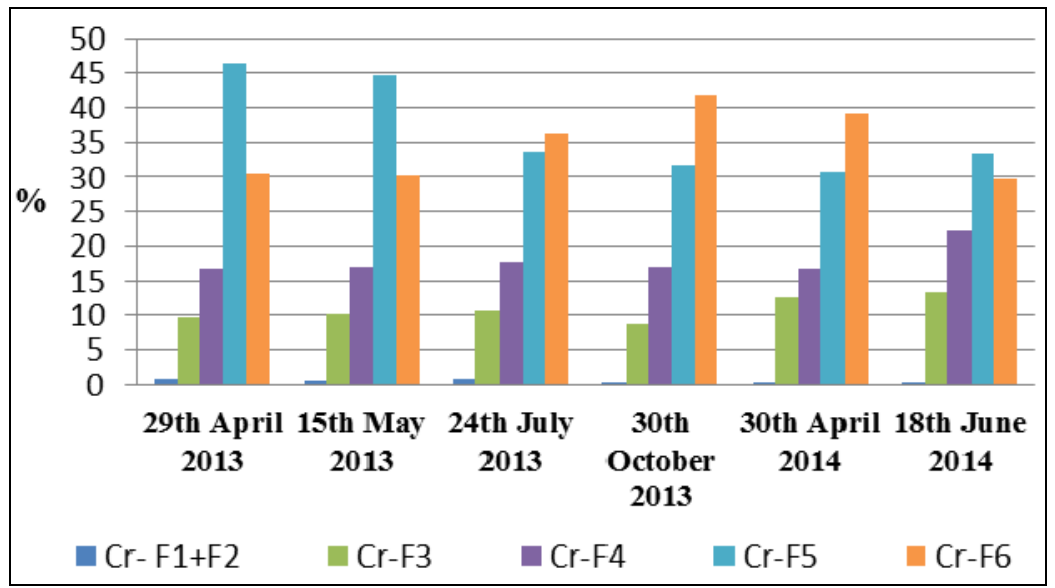

Figure 2. The chromium concentration in bulk $A$

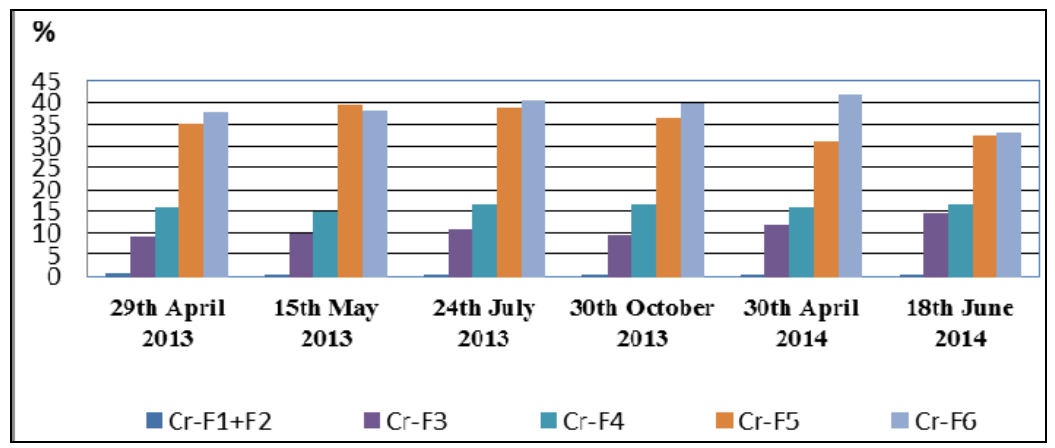

Figure 3. The chromium concentration in bulk $B$

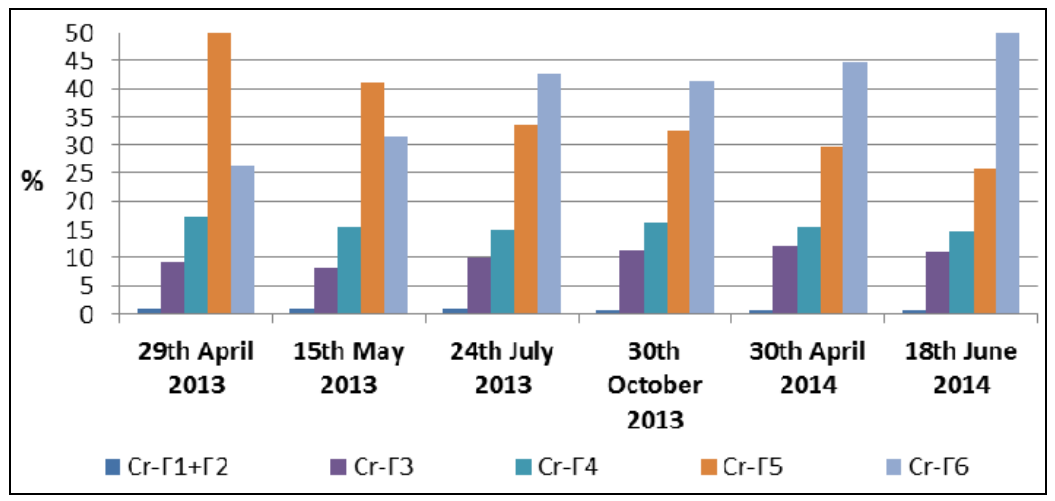

Figure 4. The chromium concentration in bulk $\mathrm{C}$ 


\section{The copper evolution}

The total form of copper concentrations were below the value of $8400 \mathrm{mg} \mathrm{kg}^{-1}$ provided by the Romanian regulations [12]. In the bulk $\mathrm{A}$, the total form of copper concentration was lower by $1.57 \%$ than the initial one, while in bulks $B$ and $C$ the values increased by $1.72 \%$ and $2.13 \%$, respectively. This might be due to the cattle manure addition in bulk $A$ which positively influenced the copper evolution (Figure 5).

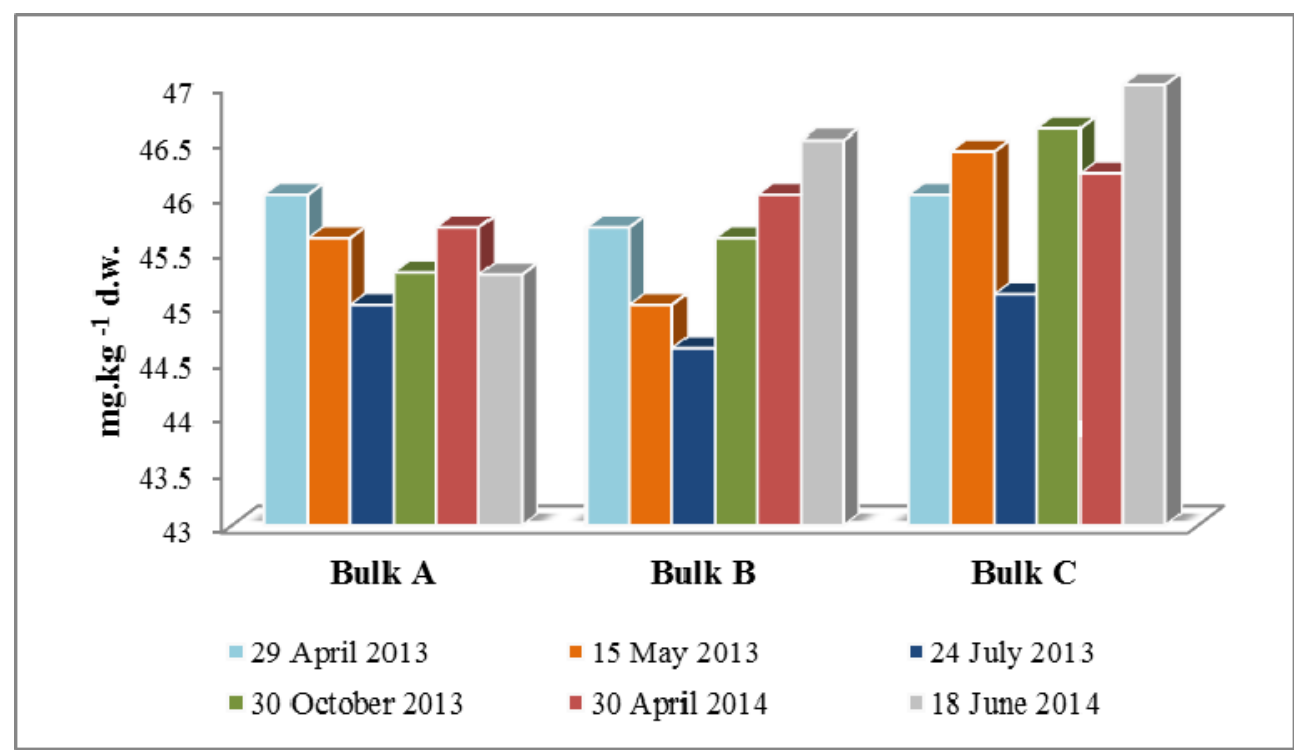

Figure 5. The total form of copper in compost

The sequential analysis revealed the lowest values of the bioavailable copper forms for plants in bulk $A(1.01 \%)$ and the highest values $(1.23 \%)$ in bulk $C$ in the thermophile phase of composting. Similar with other research results $[14,15]$, the highest copper concentrations are contained by forms F5 and F6 (sulfides „mobilisable”) and residual, respectively (Figure 6, 7, 8). The correlation coefficients were identified only for bulk $C$ for forms $F 4$, F1 and F2 (Table 24 ). 


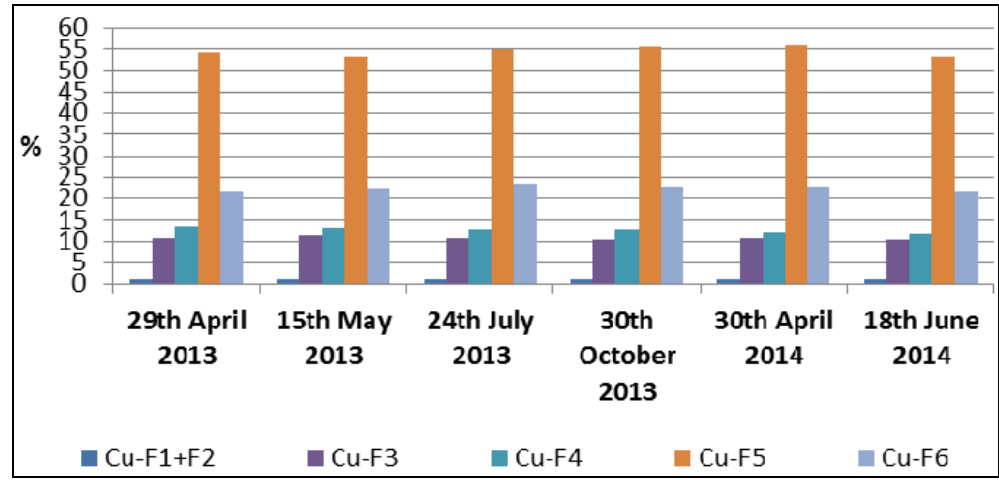

Figure 6. The copper concentration in bulk $A$

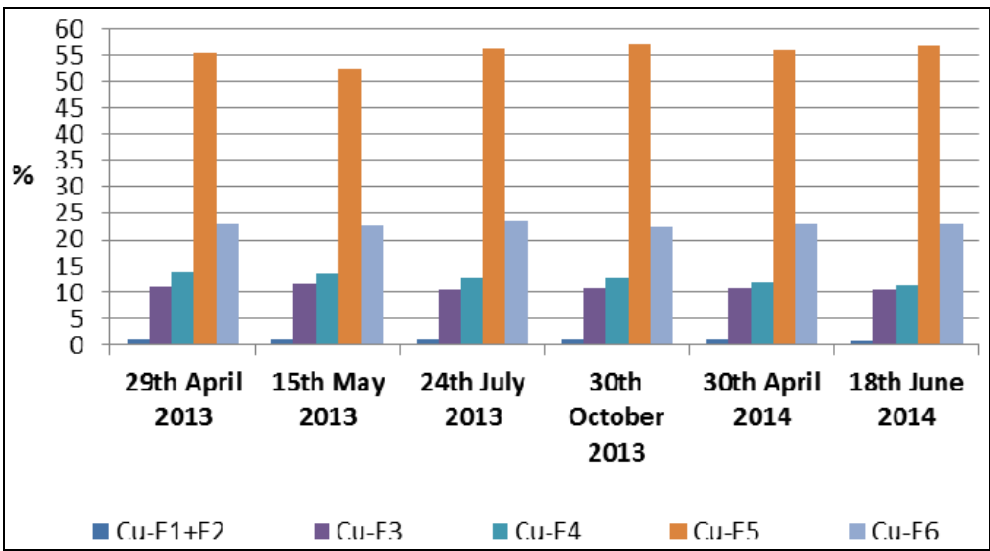

Figure 7. The copper concentration in bulk $B$

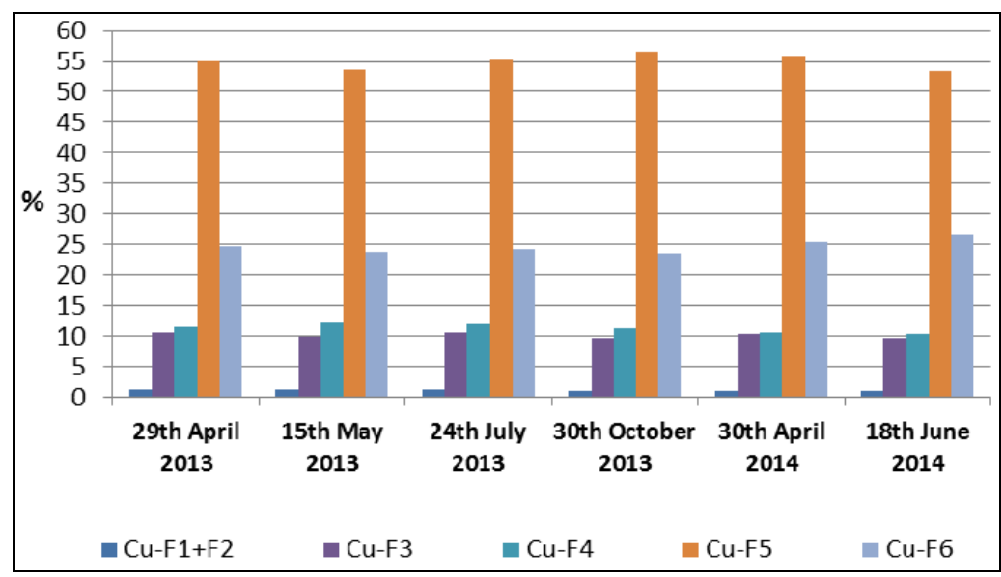

Figure 8. The copper concentration in bulk $\mathrm{C}$ 


\section{The zinc evolution}

The zinc concentration value determined for each compost bulk did not exceed the maximum value concentration of $7500 \mathrm{mg} \mathrm{kg}^{-1}$ provided by the Romanian in force regulations [12] (Figure 9). In each bulk the final total zinc value decreased by 1.49 times (bulk A), 1.48 times (bulk B) and 1.36 times (bulk $C$ ) towards to the initial value (Figure 10, 11, 12). Similar results revealed by other papers showed the same negative trend for zinc in composting process $[14,15]$.

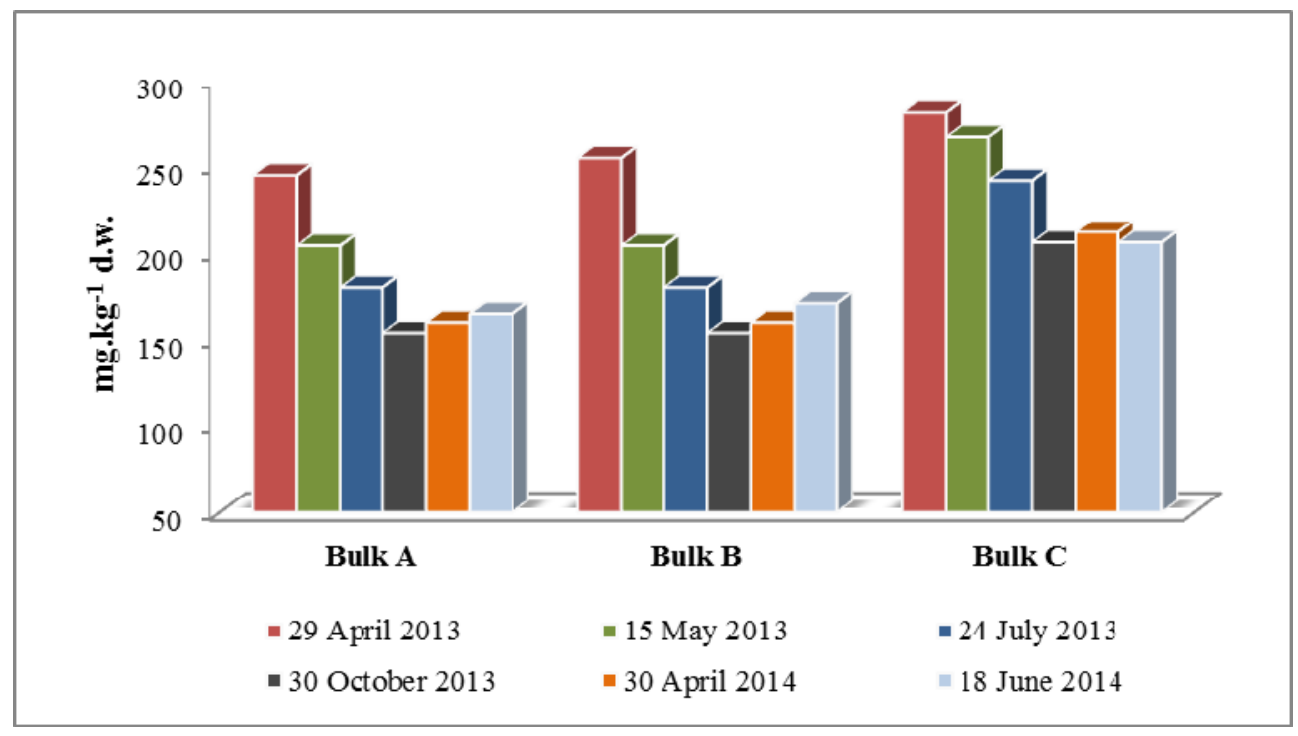

Figure 9. The total form of zinc in compost

The highest bioavailable percent for the zinc form for plants (F1+F2) was identified in bulk $A(1.46 \%)$ at the beginning of the composting. This might be explained by the presence of organic additives in the bulks $A$ and B. Referring to the correlation coefficients for zinc, distinct significantly values have been identified among the exchangeable „mobile” form (F1) and total form, in bulk $A$ and $C$ (Figure 10,11,12). It was possible that the cattle manure to stimulate the zinc leaching in close correlation with the $\mathrm{pH}$ evolution. 
STUDY REGARDING THE PRESENCE OF SOME HEAVY METALS ...

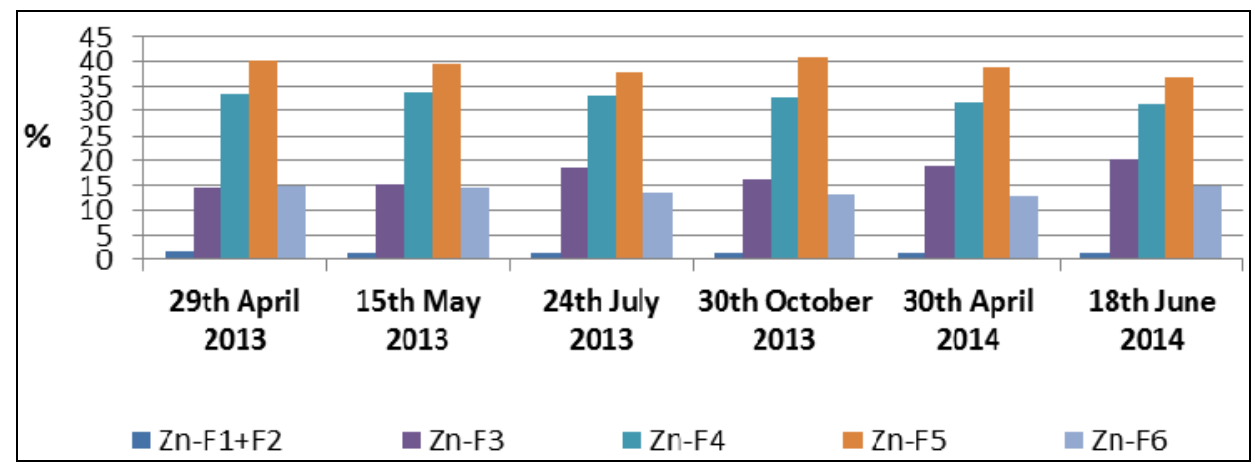

Figure 10. The zinc concentration in bulk $A$

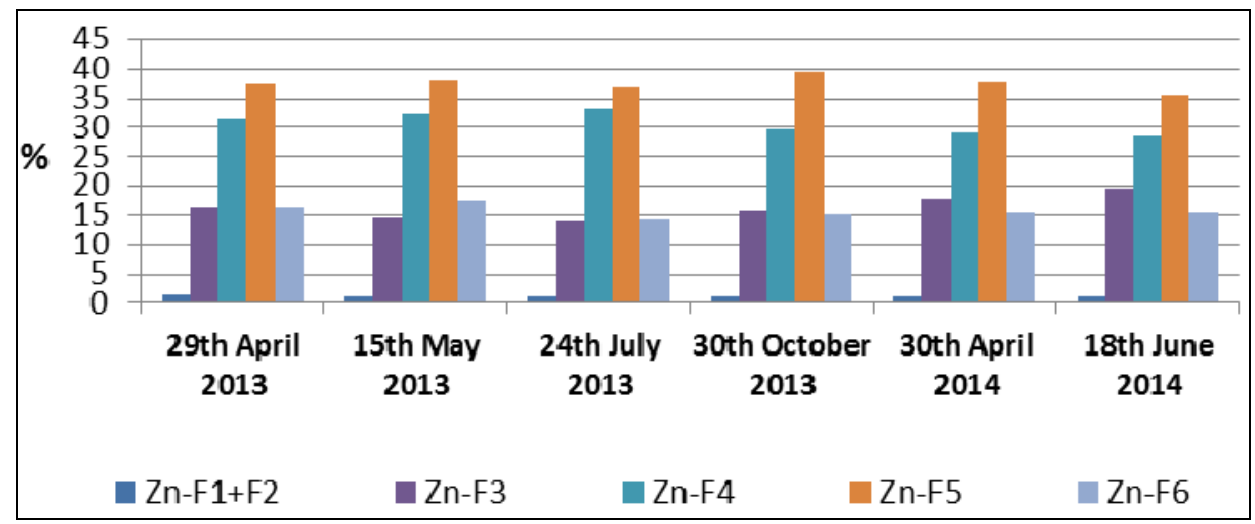

Figure 11. The zinc concentration in bulk B

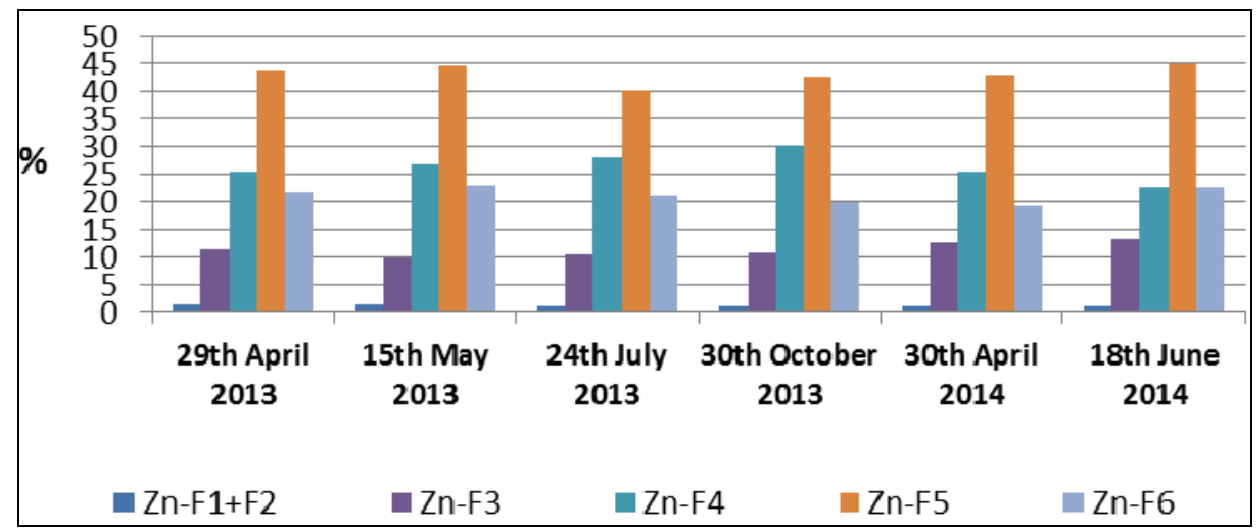

Figure 12. The zinc concentration in bulk $C$ 


\section{The manganese evolution}

The total form of manganese showed a negative evolution in bulks $A$ and $B$ and almost constant one in bulk $C$ (Figure 13). The highest decrease was noticed in bulk $B$ (1.25 times). The total form of manganese ranged from $62.5 \mathrm{mg} \mathrm{kg}^{-1}$ in bulk $B$ at the final composting and $79 \mathrm{mg} \mathrm{kg}^{-1}$ in bulk $C$ at the beginning of the composting process (Figure 14, 15, 16). The manganese values are not provided by the Romanian in force regulations [12].

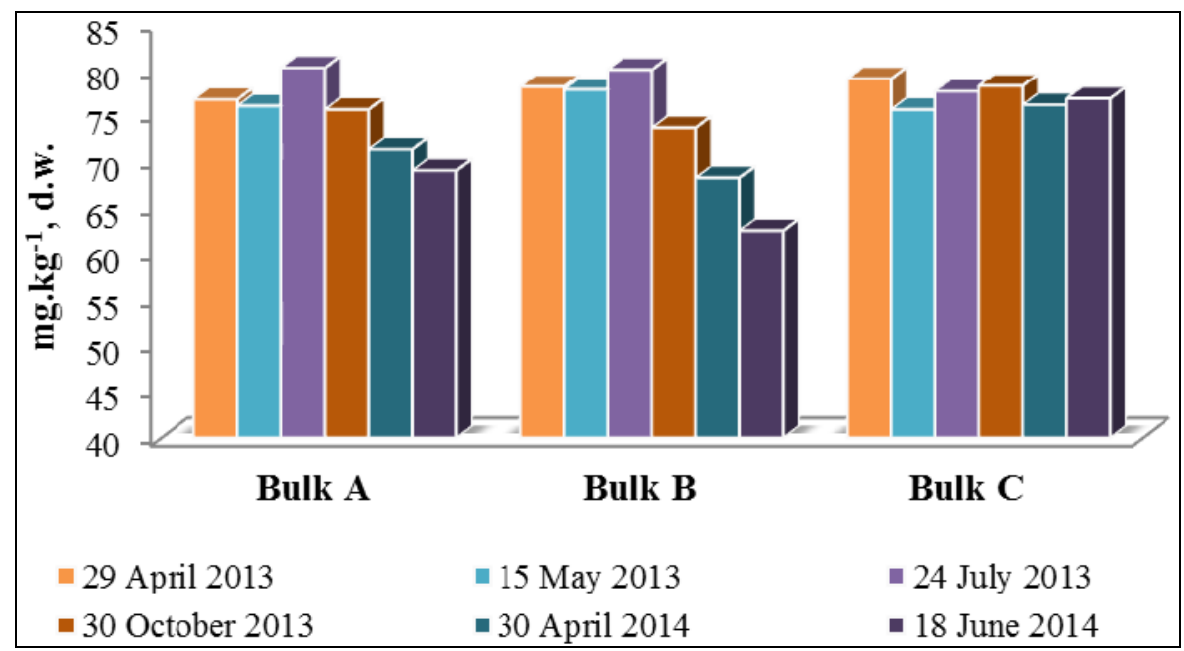

Figure 13. The total form of manganese in compost

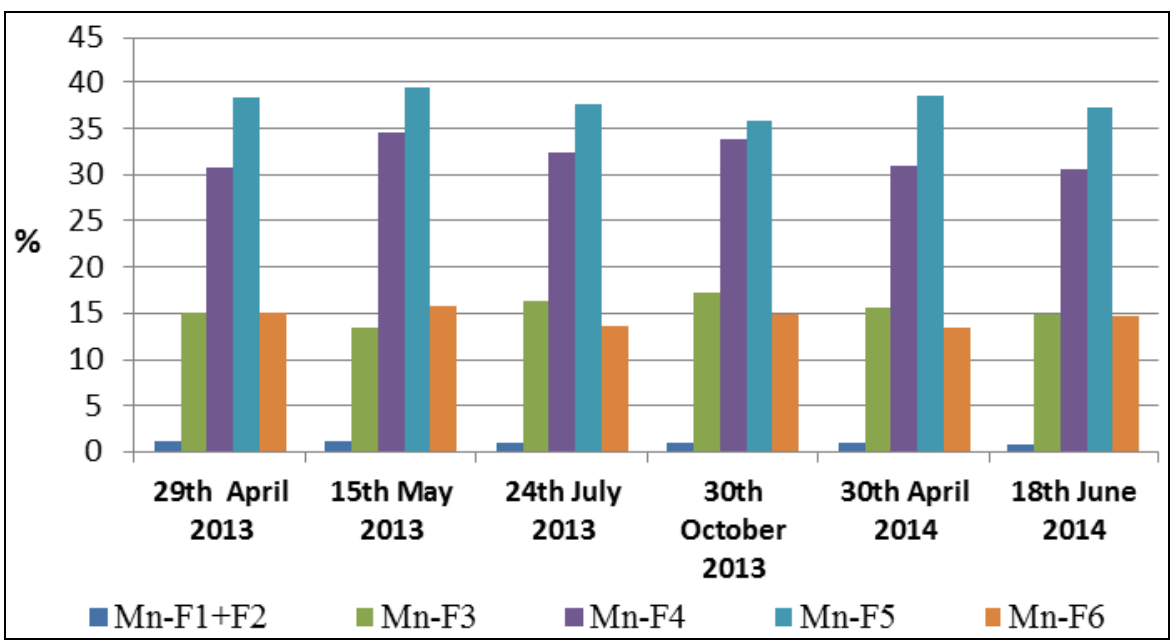

Figure 14. The manganese concentration in bulk $A$ 


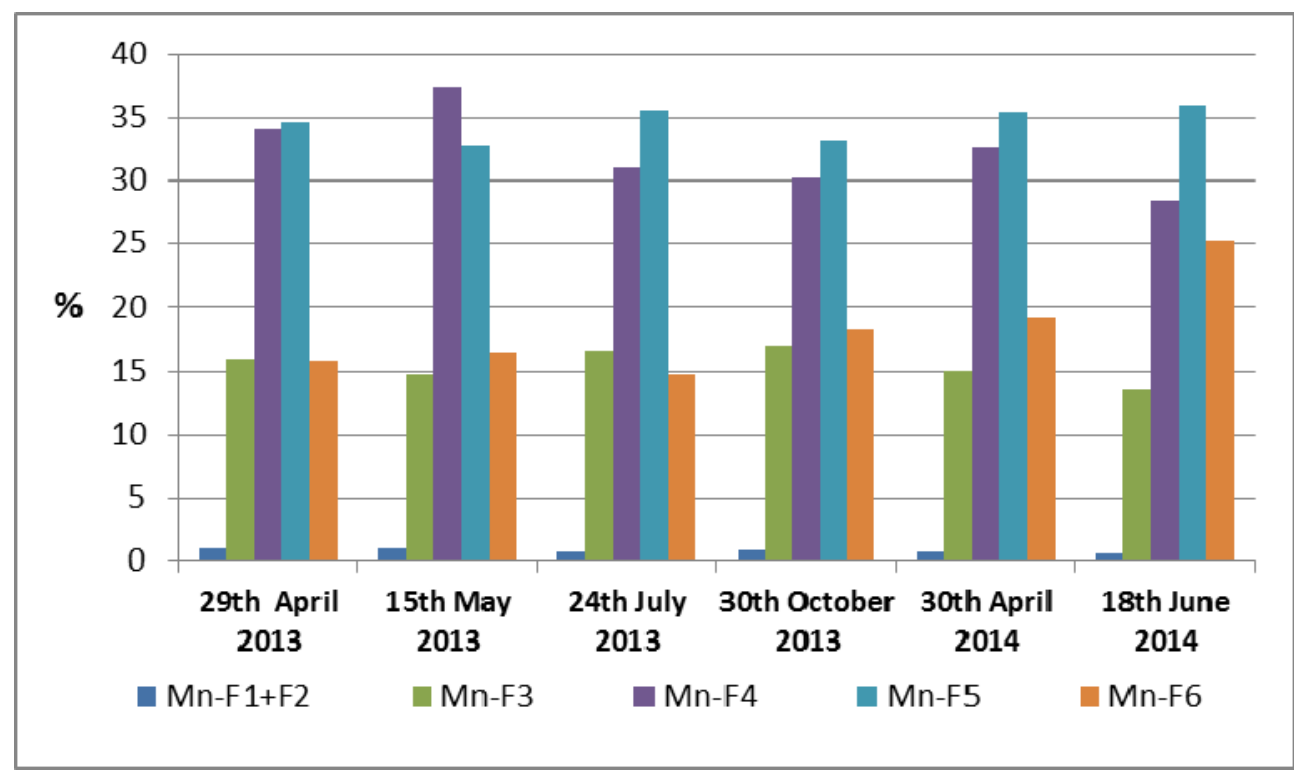

Figure 15. The manganese concentration in bulk B

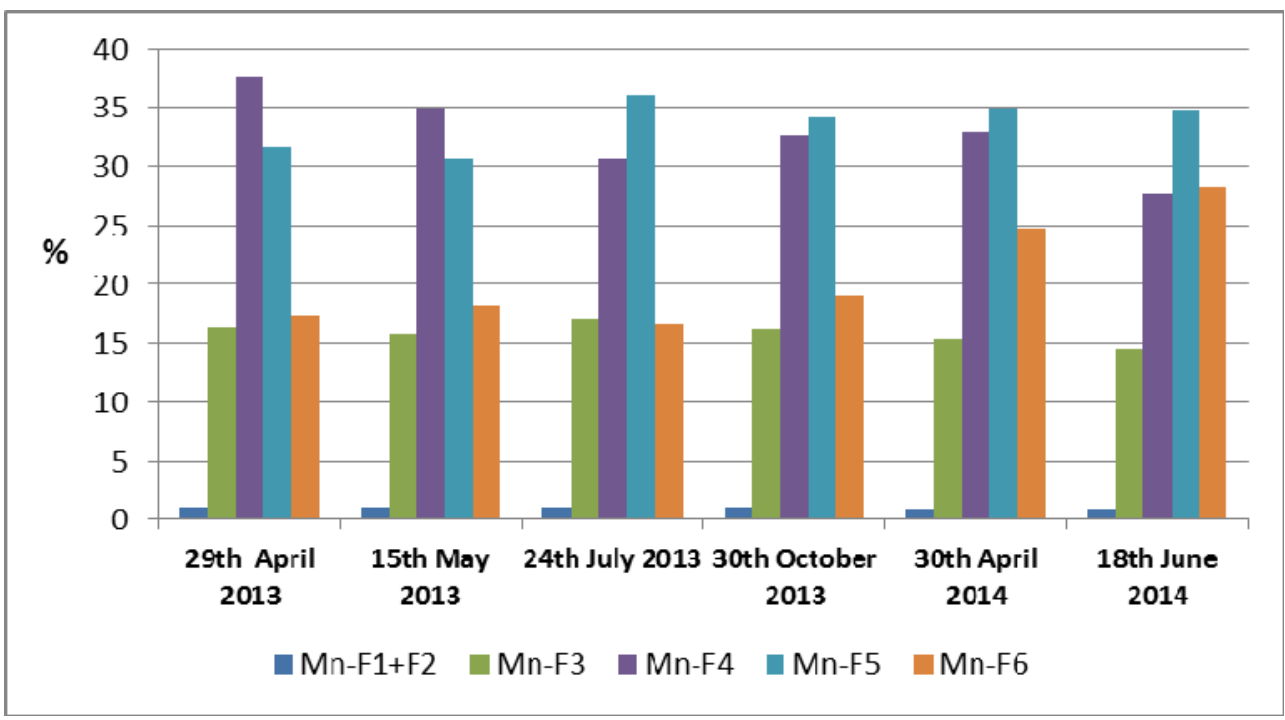

Figure 16. The manganese concentration in bulk $\mathrm{C}$ 
At the final composting, the percentage of bioavailable magnesium for plants uptake $(F 1+F 2)$ increased as follows: bulk $B<$ bulk $C<$ bulk $A$. It was obvious that the organic additive used in bulk $B$ influenced the manganese leaching. The highest percentages of manganese were noticed for forms F4 and F5, namely the "mobilisable" forms in the sulfide and carbonates, or organically complexed forms where the additives probably did not allow the manganese releasing from this forms. The similar trend of manganese for forms F1 and F2 was revealed by other researches [14, 16]. The correlation coefficients of the manganese and humic substances were statistically insignificant but there were significant correlations among various metal forms (Table 2).

\section{CONCLUSIONS}

The total form of the analyzed metallic elements did not exceed the maximum limits, neither at the beginning nor at the end of composting.

The bioavailable and unavailable metal forms for plants determined by sequential analysis showed similarities in relation to the percentages of extracted forms.

The lowest percentages were for the bioavailable metal forms for uptake of the plants. Thus, the succession $F 6>F 5>F 4>F 3>(F 1+F 2)$ was characteristic for chromium, the succession $F 5>F 6>F 4>F 3>(F 1+F 2)$ for copper and zinc and the succession $\mathrm{F} 5>\mathrm{F} 4>\mathrm{F} 6>\mathrm{F} 3>(\mathrm{F} 1+\mathrm{F} 2)$ for manganese.

In accordance with the experiment results it can be concluded that the manure additives positively influenced the composting.

\section{EXPERIMENTAL SECTION}

The preparation of the bulks and sampling the compost for physico-chemical analysis

The three bulks of bio-waste consisted in a mixture of wood chips, fresh grass, dry leaves, hay. In addition to this, about $8 \%$ cattle manure was added to the bulk $A$ and about $11 \%$ of poultry manure to the bulk $B$. The bulk $C$ had no manure.

The bulks preparation method, the compost sampling and the physico-chemical properties of the compost (table 3 ) are presented in detail in the paper "Influence of Some Natural Organic Additives on the Quality of Vegetal Compost" [11].

To establish the proportions of materials subjected to the composting process the data from the literature on the C:N ratio were used for each type of material according to table 3 . 
Table 3. The C: $\mathrm{N}$ ratio of the materials included in composting process [17]

\begin{tabular}{|c|c|}
\hline Ingredient of compost & Ratio C:N \\
\hline Wood chips & $400: 1$ \\
\hline Poultry manure & $12: 1$ \\
\hline Dry leaves & $35: 1$ \\
\hline Fresh grass & $20: 1$ \\
\hline Cattle manure & $16: 1$ \\
\hline Hay & $25: 1$ \\
\hline
\end{tabular}

By Davidescu and Davidescu [18] the nutrients content in the cattle and poultry manure (total $\mathrm{N}, \mathrm{P}_{2} \mathrm{O}_{5}, \mathrm{~K}_{2} \mathrm{O}$ ) are showed in table 4 .

Table 4. The nutrients content in the cattle manure and the poultry manure [18]

\begin{tabular}{|c|c|c|}
\hline \multirow{2}{*}{ Nutrient } & Cattle manure & Poultry manure \\
\cline { 2 - 3 } & \multicolumn{2}{|c|}{ (\%, dry weight) } \\
\hline Total $\mathrm{N}$ & $0.7-2$ & $3-5$ \\
\hline $\mathrm{P}_{2} \mathrm{O}_{5}$ & $0.3-1.2$ & $2-3$ \\
& $(0.13-0.52$ in $\mathrm{P})$ & $(0.08-1.3$ in $\mathrm{P})$ \\
\hline \multirow{2}{*}{$\mathrm{K}_{2} \mathrm{O}$} & $0.8-0.9$ & $1.1-2.5$ \\
& $(0.6-0.7$ in $\mathrm{K})$ & $(0.9-2$ in $\mathrm{K})$ \\
\hline
\end{tabular}

At the end of the 15 months (29th April $2013-21^{\text {st }}$ July 2014) of composting, samples from every bulk were taken and analyzed in the laboratory [11].

\section{Sampling and preliminary preparation of compost to determine the characteristics}

The Protocol used in this research provided that the samples of each pile must be taken after removing a layer of $5-10 \mathrm{~cm}$. The representative sample was obtained by application of the quarter method [19] on the sample resulted from the mix of 6 samples of about $1 \mathrm{~kg}$ each other, sampled from each pile.

The study protocol provided that the samples of each pile were taken after removing a layer of $5-10 \mathrm{~cm}$ and the representative sample that arrived in the laboratory was obtained after applying the quarter method [19] on the sample obtained by homogenizing 6 samples of approx. $1 \mathrm{~kg}$, taken from each pile. For the physico-chemical analysis, the samples were prepared according to "Methods Book for the Analysis of Compost" [19].

To determine the conductivity the samples were ground to size $<10$ $\mathrm{mm}$ and analyzed in fresh state. 


\section{Chemical analysis}

To make the chemical analyses of the compost a representative sample was taken from each bulk $(A, B, C)$ of the homogenized compost at various time of decomposing process.

Thus, the conductivity was potentiometric determined, using a ratio of 10:1 of double-distilled water suspension and compost. It was measured with a laboratory conductometer, Orion 3 Star type, manufactured by Thermo Scientific. The quantification limit of the method is $3 \mu \mathrm{S} \mathrm{cm} \mathrm{cm}^{-1}$.

The total form of the trace metalic elements $(\mathrm{Cr}, \mathrm{Cu}, \mathrm{Zn}, \mathrm{Mn})$ was determined from the acidic digestions of the sample. The digestion was made according to the „Digestion Application Note DG-EN-04 for Milestone microwave oven" [20]. In this regard, $0.25 \mathrm{~g}$ of the each compost sample was mineralized with $7 \mathrm{ml}$ of $\mathrm{HNO} 365 \%, 1 \mathrm{ml}$ of $\mathrm{HCl} 37 \%, 1.5 \mathrm{ml}$ of $\mathrm{HF} 40 \%, 45$ minutes at $240^{\circ} \mathrm{C}$. After dissolution, volumetric solution was directly analyzed by flame atomic absorption ( $\mathrm{Mn}$ and $\mathrm{Zn}$ ) and graphite furnance $(\mathrm{Cu}, \mathrm{Cr}$ ), using the Perkin Elmer spectrophotometer, type Aanalyst 700. The bioavailable and unavailable metals for plants were determined according to the method of Sposito [21]. This procedure is also used in various researches regarding the metals state $[22,14]$. The extractable metals were analyzed using a ratio of 1:4 of compost and different extractant solutions by flame atomic absorption $(\mathrm{Mn}$ and $\mathrm{Zn})$ and graphite furnance ( $\mathrm{Cr}$ si $\mathrm{Cu}$, table 5). Each result was obtained as an average of three individual readings of the analyzed sample. It was validated with the relative standard deviation using the equipment software - WinChemLab. The used calibration curves were validated using the quality coefficient (R2), being acceepted only values $\geq 0.990$.

The content of each metal in the soil matrix was established after achieving the extraction in accordance with the protocol of the sequential extraction, provided by table 5 .

Table 5. Experimental conditions used to determine extractable metals, in accordance with the method of Sposito [11, 14, 21, 22]

\begin{tabular}{|c|c|c|}
\hline Heavy metals & $\begin{array}{l}\text { Extractant } \\
\text { solution }\end{array}$ & $\begin{array}{l}\text { Duration } \\
\text { of shaking }\end{array}$ \\
\hline F1 - Exchangeable - „mobile” & $\mathrm{KNO}_{3} 0.5 \mathrm{M}$ & 16 hours \\
\hline F2 - Soluble -„mobile” & $\mathrm{H}_{2} \mathrm{O}$ & $\begin{array}{l}2 \text { hours, for } \\
\text { three times }\end{array}$ \\
\hline F3 - Organically bound - „mobilisable” & $\mathrm{NaOH} 0.5 \mathrm{M}$ & 16 hours \\
\hline $\begin{array}{c}\text { F4 - Organically complexed or carbonates - } \\
\text { „mobilisable” }\end{array}$ & EDTA $0.5 \mathrm{M}$ & 6 hours \\
\hline F5 - Sulfides - „mobilisable” & HNO3 $4 \mathrm{M}$ & 6 hours at $80^{\circ} \mathrm{C}$ \\
\hline
\end{tabular}


The ashed residue obtaining from the last step of the sequential extraction was subjected to the digestion procedure using a mixture of $\mathrm{HNO} 3,65 \%$ with $\mathrm{HCl} 37 \%$ (volume ratio 1:1). It was put in Teflon tubes which was inserted in a microwave oven (Milestone type), for 30 minute at $220{ }^{\circ} \mathrm{C}$ $[11,23]$. This metal form is called "Residual fraction - F6" [22, 23].

\section{REFERENCES}

1. J. Martinho, B. Campos, I. Brás, E. Silva, Environment Protection Engineering, 2015, 41, 2, 57.

2. G. Chen, G. Zeng, C. Du, D. Huang, L. Tang, G. Wang Land Shen, Journal of Hazardous Materials, 2010, 181, 211.

3. J. Singh, A. S. Kalamdhad, International Research Journal of Environment Sciences, 2013, 2, 4, 59.

4. P. Castaldi, L. Santona, P. Melis, Fresenius Environmental Bulletin, 2006, 15, 9b, 1133.

5. K.G. Scheckel, R.L. Chaney, N.T. Basta, J.A. Ryan, Advances in Agronomy Elsevier, 2009, 104, 52.

6. M. Vukobratović, Z. Vukobratović, Z. Lončarić, D. Kerovac, Acta Horticulturae 1034: International Symposium on Growing Media and Soilless Cultivation, 2014, 75, 591.

7. I. Smical, V. Hotea, V. Oros, J. Juhasz, E. Pop, Environmental Engineering and Management Journal, 2008, 7, 5, 609.

8. A.K. Gupta, S. Sinha, Bioresource Technology, 2007, 98, 1788.

9. F. Ingelmo, M.J. Molina, M. Desamparados Soriano, A. Gallardo, L. Lapeña, Journal of Environmental Management, 2012, 95, 104.

10. J. Singh, A.S. Kalamdhad, Ecological Engineering, 2013, 52, 59.

11. I. Smical, A. Muntean, V. Micle, Environmental Engineering and Management Journal, 2016, 15, 5, 1041.

12. National Institute of Research-Development for Pedology, Agrochemistry and Environmental Protection - IRPA, Bucharest, Romania (NIRDPAEP-IRPA) 2014 Codes of good practices. Composting (http://www.icpa.ro/Coduri/Compostarea.pdf), 6.

13. M. Ardelean, Academic Press Cluj Napoca, 2008.

14. M. Ahmed, A. Idris, S.R.S. Omar, Journal of Engineering Science and Technology, 2007, 2 81-94.

15. B. Manohara, S.L. Belagali, International Journal of Innovative Research in Science, Engineering and Technology, 2014, 3, 2, 9664.

16. Z. Y. Hseu, Bioresource Technology, 2004, 95, 53.

17. C. Bachert, W. Bidlingmaier, S. Wattanachira, Handbook on composting in uncovered piles (rows), European Compost Network ECN/ORBIT, 2008. 
18. D. Davidescu, V. Davidescu, Romanian Academy Publishing House Bucharest, $1992,133$.

19. Federal Compost Quality Assurance Organisation (FCQAO) and Bundesgütegemeinschaft Kompost e.V. (BGK), Federal Compost Quality Assurance Organisation (FCQAO) and Bundesgütegemeinschaft Kompost e.V. (BGK), 2003, 6.

20. Digestion Application Note DG-EN-04, Fly Ash, Milestone Microwave Laboratory System, 1.

21. G. Sposito, L.J. Lund, A.C. Chang, Soil Science Society of America Journal, 1982, 46, 260.

22. H.E. Qingsong, Y. Ren, I. Mohamed, M. Ali, W. Hassan, F. Zeng, Soil \& Water Res., 2013, 8, 71.

23. Digestion Application Note DG-EN-08 - in accordance with USEPA Method 30511998 Microwave assisted acid digestion of sediments, sludge, soils, and oils, Washington, DC: U.S. Environmental Protection Agency Office of Wastewater Management, 1. 